\title{
The Implementation of Structural System Analysis and Information Technology to Business Process Re-Engineering
}

\author{
Mahmoud Z. Mistarihi, Ph.D.
}

\begin{abstract}
Business Process Reengineering provides an efficient and effective change in the way in which work is performed. During the traditional system development life cycle, there are some limitations within the system analysis stage such as poor communication and lack of a common language between the user and the analyst and between the analyst and the designer. To tackle this challenge, this paper presents an integrated methodology of Structural System Analysis and Information Technology.. The real data based on a case study at mix Grill restaurant in Irbid - Jordan is collected then

analyzed using the proposed technique to build data and process model. All results demonstrate that the proposed method is both effective and efficient for Business Process ReEngineering. In fact, it can significantly enhance the business process and thus, gain and sustain the competitive advantage.
\end{abstract}

Keywords - Structural System Analysis (SSA); Business Process Reengineering (BPR); Data flow Diagram (DFD); Competitive advantage.

\section{Motivation}

The basic tools and concepts of structured analysis and the transition to structured design will be introduced. The impact of structured analysis on the traditional system development life cycle (SDLC) will be enhanced. In systems analysis process, there are three major problems [1]: Firstly, the analysis process is imprecise, incomplete, and haphazard. Secondly, the inaccurate communication between the analyst and the user on the one hand and the designer or programmer on the other. Thirdly, it doesn't contain logical sense. The core issue of success or failure of any project is how to gain and sustain the competitive advantage. Projects go wrong for a variety of reasons: misunderstanding of user's needs, the dynamic change for user's needs, misunderstanding between analysts and designers and/or between designers and programmers and inflexible design at a global level [2].

The proposed method provides a set of tools designed to solve these problems. It reduces the gap between analysis and design; it produces a system that completed on-time and within budget, meets a stated set of business objectives and

Mahmoud Z. Mistarihi

Yarmouk University

Irbid, Jordan good system in the sense of being reliable, flexible and maintainable.

\section{Introduction and Background}

The basic phases for traditional System Development Life (SDLC) is described in "Fig. 1".

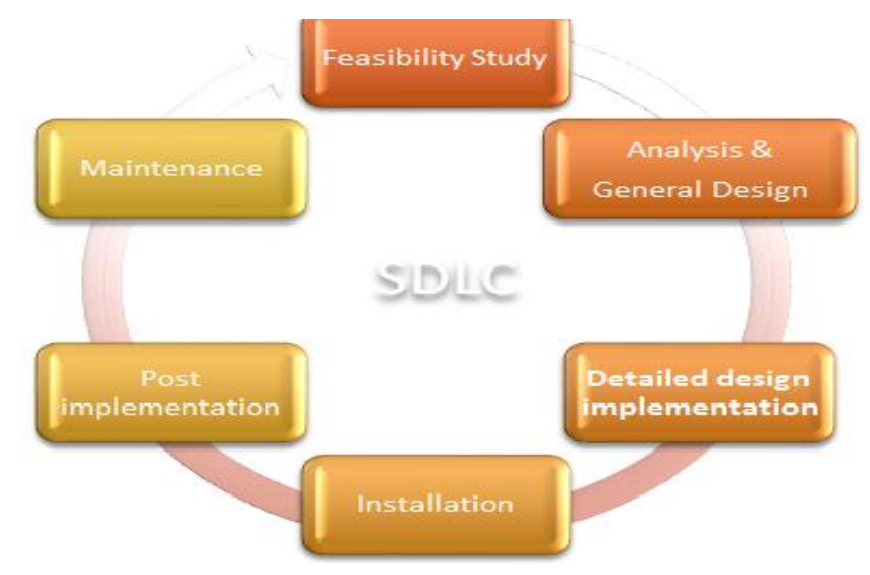

Figure 1. Basic phases for traditional System Development Life

Analysis phase is more critical than other activities in SDLC in determining the success of a system. The traditional SDLC analysis have several weaknesses that adversely affect the resulting system [2]. When the analysis ends without: a well-defined standard for the system specification document, the requirements are often incomplete or inaccurate, clear communication between the user and the analyst that results in an accurate, total specification is critical. Without it, there is no assurance that the real needs will be met. The System Specification must bridge the gap from analysis and general design to detailed design and implementation. It establishes the measures of "success" against which the system can be judged throughout the SDLC. It should support the analysis phase in SDLC and it must concentrate on the logical requirements, avoiding the constraints imposed by physical trappings. It is the main communication medium between the analyst and the designer and should be free of any design-bias. Structured analysis is described below in "Fig. 2". 


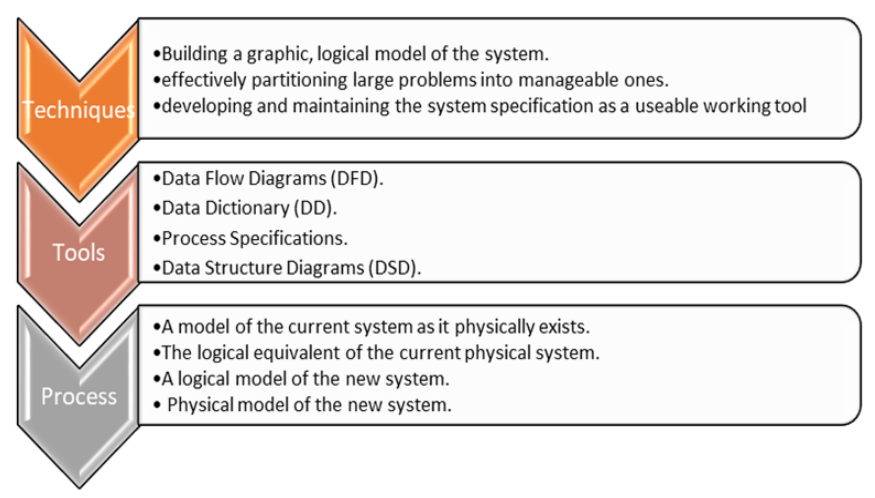

Figure 2. Structured analysis flowchart

\section{Proposed Business Process Reengineering Methodology}

The proposed structural system analysis and information technology methodology to Business Process ReEngineering undergoes the following steps; Specify the new system in such a way that the user, analyst, and designer all have a clear, mutual understanding. The capabilities of the system must be fully specified by defining the data that is needed. The transformations that will be applied, and the performance, security, and controls that are required. Specify the extent to which these processes will be automated and establish a man-machine interface. Moreover, the system specification should communicate these steps in a clear, concise, and precise fashion using target specification by modeling the existing and new proposed physical and logical systems. Then, package the selected alternative.

\subsection{The data flow diagram (DFD)}

Traditionally, systems are studied from a procedural viewpoint. This approach often results in a narrow, fragmented understanding of the system (flow of control) [3]. The DFD's represents a meaningful change in the way a system is viewed. The use of a DFD provides a more clear and global understanding of the system. (Logical flow of data) [1]. The DFD presents a meaningful model of the system. Advantages of the modeling process [4]: It provides the capability of "seeing" how the system will react when implemented and data is supplied to it, effective analytic tool, leading the analyst to question areas where understanding is not yet complete or is visibly incorrect, effective communication tool between user and analyst as well as analyst and designer. Moreover, it is an effective tool for partitioning a system and representing the interrelationships between the resulting components. "Fig. 3" highlights the DFD process.
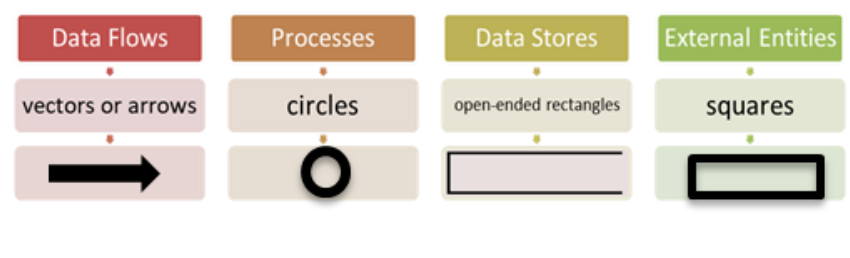

Figure 3. The data flow diagram (DFD) process

How to draw the DFD level zero (starting point) [5]: identifying the net sources and sinks of data, then identifying all data flows between the system and the external entities. Finally drawing a context diagram. Regarding the top-level partitioning of the system(Network): focus should be on the major processes, intermediate data flows and data stores necessary to model the system which transforms the major system inputs to its outputs. To draw the fragmented portions of the DFD (Completed network): identify the existence of processes and data stores but do not label until data flows have been named. Then, label each data flow with a name that is an honest, meaningful, and complete description of its content. After that consideration of control aspects such as loops, decisions, starting, and stopping.

A successful system model is the product of many iterations. With each iteration new insights and understandings are gained. DFD is not easily understood because too much detail is presented in one drawing [6].

\subsection{The Data Dictionary (DD)}

Meaningful names have been given to each data flow, data store, and process in DFD Network [7]. These names aid in understanding but don't specify the system. The data and the processes must be fully defined, so that users, analysts, and designers have a correct and complete understanding of the system. The Data Dictionary (DD) will contain the definitions of all data referenced in the system and a process specification. The DD is used primarily for reference purposes and to maintain consistency in naming and specifying the characteristics of the data throughout the system [8]. 
Proc. of the Seventh Intl. Conf.on Advances in Computing, Communication and Information Technology - CCIT 2018 Copyright ( Institute of Research Engineers and Doctors, USA. All rights reserved.

ISBN: 978-1-63248-162-7 DOI:10.15224/978-1-63248-162-7-26

TABLE 1. TYPES OF ENTRIES IN THE DATA DICTIONARY.

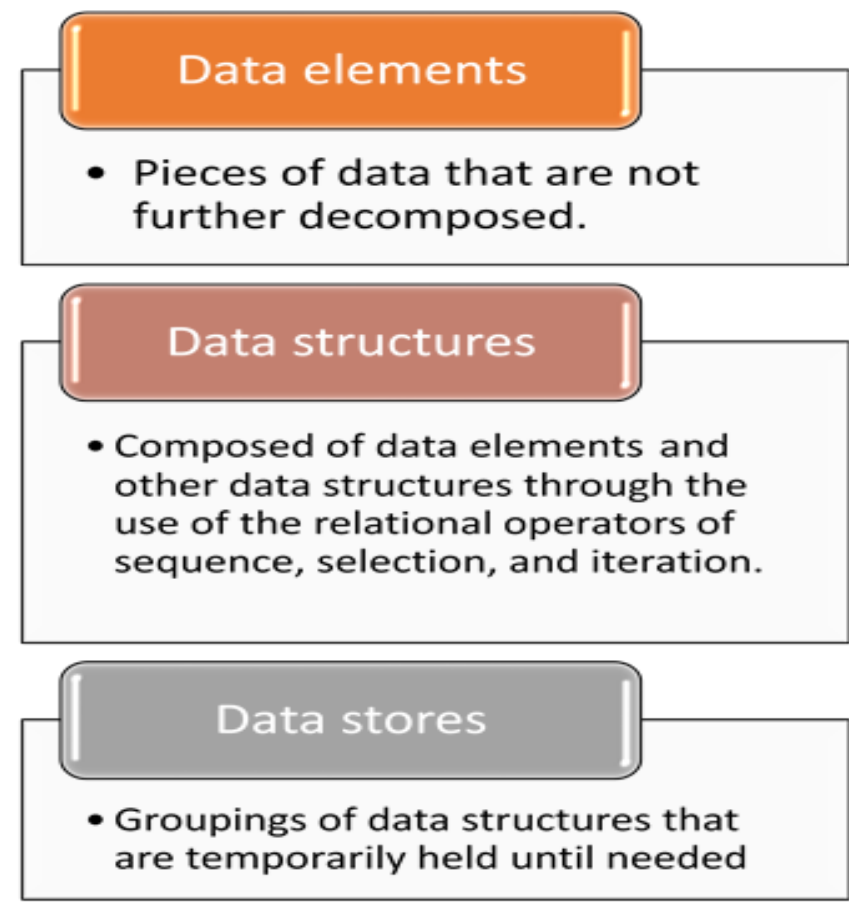

The data definition portion of a typical DD may contain thousands of entries. These entries fall into three types as described in Table 1.The analyst can specify a process in such a way that given a particular set of values for the incoming data flows, exactly one combination of rules applies, resulting in a unique set of values for the outgoing data flows [9].To accomplish this, three tools are introduced: Structured English, that is a restricted vocabulary which uses action-oriented verbs, omits subjects, and uses terms that are reserved or defined in the data dictionary (DD). Secondly, decision tables as excellent analytic tools in situations where the resulting actions depend on the occurrence of one of several complex combinations of independent conditions. Finally, decision trees: graphic representations of policy that are also useful in situations with combinations of several independent conditions. It is an effective way to present the results of a decision table. The DFD's must be further packaged into implementation units or jobs based on: the centralization vs. decentralization of data and processing functions, custom
1) The type of data element: discrete or continuous.

2) The size of length for discrete data, a list of values and meanings.

3) for continuous data, ranges of valid values and typical values

4) Any additional editing information or notes that are necessary.

1) The composition of the structure in terms of data elements and structures and relational operators that connect them

2) For data flows, information on volume, frequency, peak periods, timing, growth, and other important measurements may be recorded.

1) The composition

2) The organization and order with key data elements identified

3) Quantitative measures similar to those for data flows.

development vs the use of major commercially available application software packages and Separating functions that fall in the same business cycle into separate, cohesive jobs [10].

\section{Iv. Case Study: Mix Grill restaurant in Irbid, Jordan}

To test the tools and techniques of structured system analysis, a case study was carried out at Mix Grill fast food restaurant in Irbid, Jordan. There was no As-is model to fulfill the restaurant's mission. The proposed method is used to build the "To-Be model" to fully and deeply understand and predict customer needs to gain and sustain the competitive advantage.

To carry on the proposed method, firstly, we start in building database for the information system by collecting data about products, customers, raw materials, suppliers, and other Entities (Table 2). Then create tables representing the collected data. 
Proc. of the Seventh Intl. Conf.on Advances in Computing, Communication and Information Technology - CCIT 2018 Copyright $($ Institute of Research Engineers and Doctors, USA. All rights reserved.

ISBN: 978-1-63248-162-7 DOI:10.15224/978-1-63248-162-7-26

TABLE 2. BUILDING DATABASE FOR THE INFORMATION SYSTEM

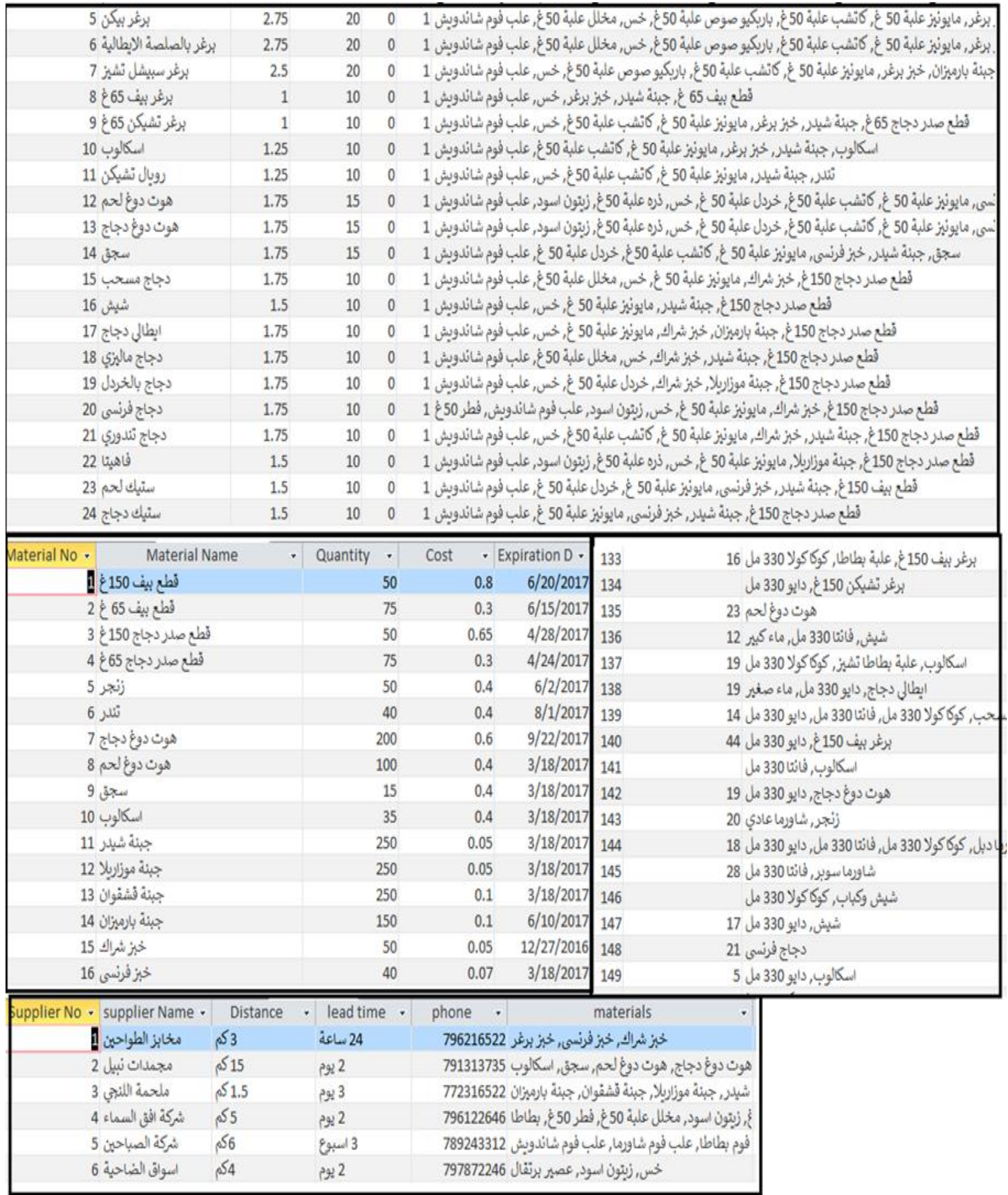


Proc. of the Seventh Intl. Conf.on Advances in Computing, Communication and Information Technology - CCIT 2018 Copyright $\odot$ Institute of Research Engineers and Doctors, USA. All rights reserved.

ISBN: 978-1-63248-162-7 DOI:10.15224/978-1-63248-162-7-26

Now, the next step is data modeling to create relationships between tables as described in "Fig. 4"

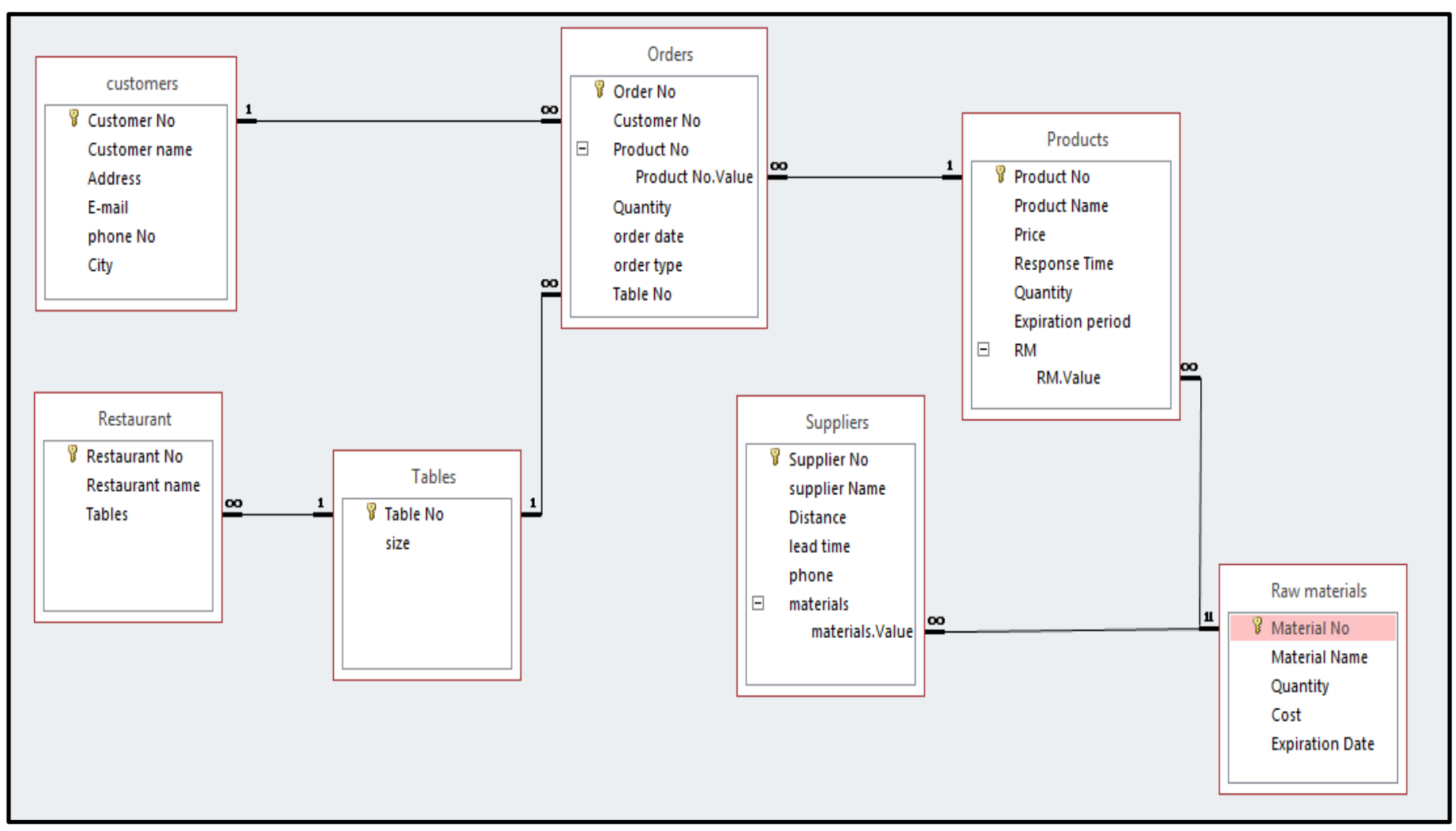

Figure 4. Data modeling process.

Then, create queries and forms as described in (Table 3).

TABLE 3. CREATING QUERIES AND FORMS FOR THE INFORMATION SYSTE

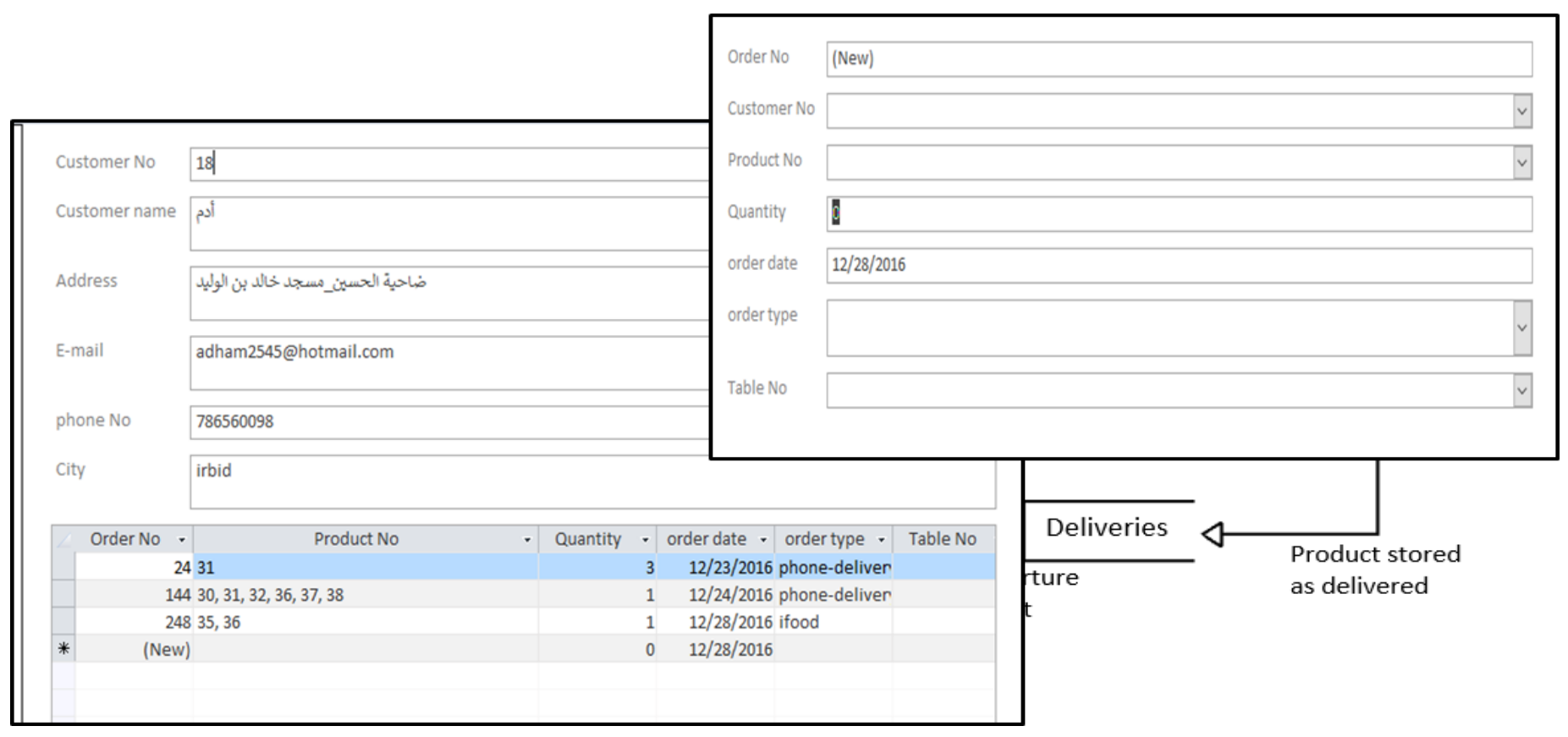




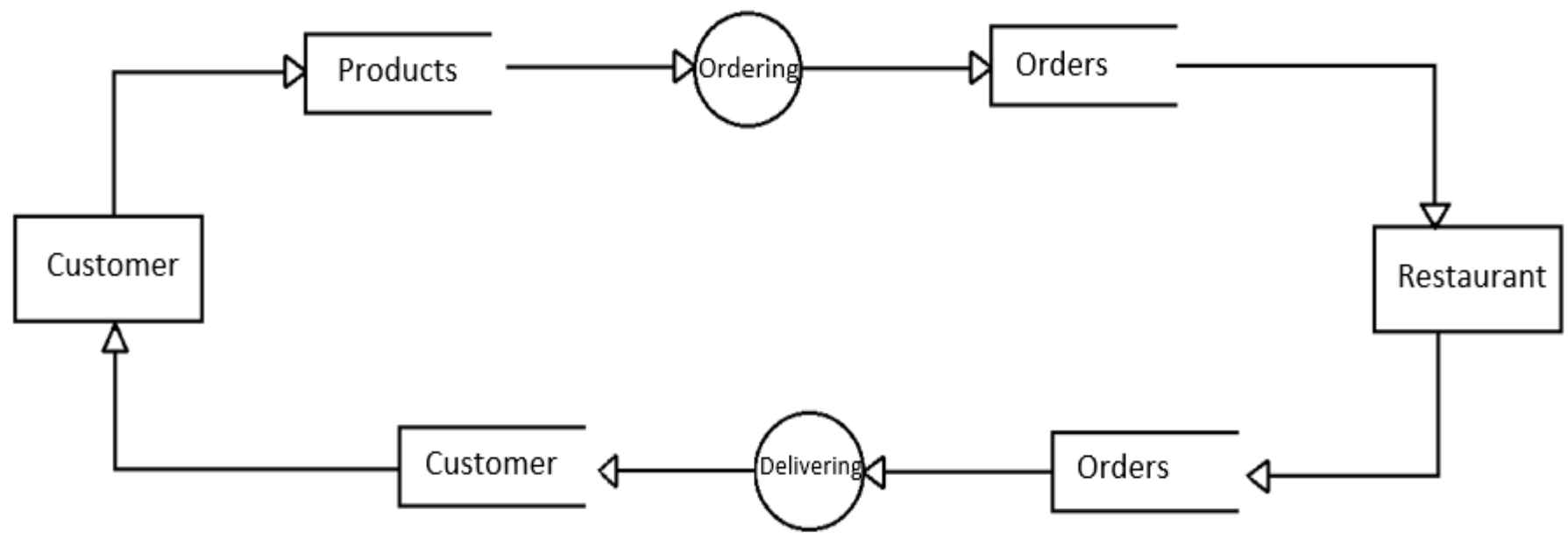

Figure 6. Data dictionary (DD) for ordering and delivering process.

Now, we will use the SSA tools to enhance the business process by matching the right structured design (process model) with the right structured analysis via Data Flow Diagram (DFD) for ordering and delivering process "Fig. 5 " and using Data Dictionary "Fig. 6".

Now, the ordering and delivering process models (logical model) are ready to give it to designer (IT) to convert it to (physical model). Results of the case study show that the proposed methodology enhances the business process by understanding the customer needs in the dynamic environment and it builds the right process model by eliminating the misunderstanding between designer (IT) and analysts (IS) and it helped in creating flexible design for global level.

\section{v. Conclusion}

The core issue of success or failure of any project depends mainly on data and process modeling to gain and sustain the competitive advantage. Projects go wrong for a variety of reasons, mainly the misunderstanding of the user's needs within a dynamic environment. In this paper, a case study at mix Grill restaurant in Irbid - Jordan is presented of the incorporation of Structural System Analysis (SSA) and Information Technology (IT) in business process re-engineering. All results recommend that the proposed method is both effective and efficient for the reengineered To-Be process. In fact, it can significantly enhance the business process in terms of throughput rate, latency and customer satisfaction. Thus, gain and sustain the competitive advantage.

\section{Acknowledgment}

Author would like to acknowledge the help of engineer Ahmad A. Bany Abed Elnabi and engineer Abdullah Mmdouh Al-Sarraj in collecting data and for their assistance via intellectual discussions.

\section{References}

[1] Mchael Hammer, "Reengineering work: don't automate, obliterate", Harvard Business Review, July-August, 1990.

[2] M. Laguna and J. Marklund, "Business Process Modeling, Simulation and Design", Prentice Hall, March 2004.

[3] Michael Hammer and James Champy, Reengineering the Corporation, Nicolas Brealey, London, 1993.

[4] Gary Bom, Process Management to Quality Improvement: the way to design, document and re-engineer business systems, John Wiley \& Sons, Chichester, 1994.

[5] "Business Process Reengineering," Technology Park Malaysia (TPM), 2015,

[Online]http://www.iscistech.com/Webpages/BusinessProcessReengi neering.aspx.

[6] Mohsen Attaran, Sharmin Attaran. The rebirth of re-engineering: Business Process Management Journal, 2004, Volume:10 Issue:4 Page: 415 - 429.

[7] Chiwoon Cho, Nam Wook Cho. Design of a BPR-Based Information Strategy Planning (ISP). Computational Science and Its Applications - ICCSA 2005, Volume 3482/2005.

[8] Malhotra, Y., Business process redesign: an overview. IEEE Engineering Management Review, 1998. 26: p. 27-31.

[9] Davenport, T.H., Process innovation: reengineering work through information technology1993: Harvard Business Press.

[10] Hammer, M., Reengineering work: don't automate, obliterate. Harvard business review, 1990. 68(4): p. 104-112. 
ISBN: 978-1-63248-162-7 DOI:10.15224/978-1-63248-162-7-26

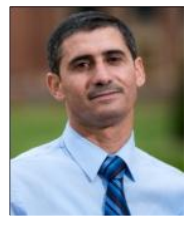

Mahmoud Z. Mistarihi is currently an assistant professor in Industrial Engineering department, Hijjawi faculty of Engineering Technology at Yarmouk University, Jordan. He earned B.S. in Applied Mathematics and Statistics from Mutah University, Jordan, Masters in Pure Mathematics from Mutah University, Jordan, Strategic studies Diploma from Royal Military Academy Sandhurst, camberley, UK and $\mathrm{PhD}$ in Industrial Engineering and Management from Oklahoma State University, USA. Dr. Mistarihi has taught courses in engineering economics, ergonomics, supply chain modeming, Operation Research and manufacturing information systems. His research interests include monitoring and diagnosis of complex systems, supply chain engineering, optimization, system identification and ergonomics. Dr. Mistarihi serves as assistant director of Jordanian military factories. He is a member of the Jordan Engineers Association (JEA), and IIE. 